\title{
Growth Mindset Contributes to Breaking Through the Dilemma of Bilingual Teaching
}

\author{
Xiaoli Meng ${ }^{1}$, Junjie Guo ${ }^{2}$ \\ Shandong Jiaotong University, Weihai, 264200, China \\ 1Xiaoli198309@163.com, 29uojie920@sina.com
}

Keyword: bilingual teaching, development bottleneck, growth mindset

\begin{abstract}
The inadequacies in ability and quantity of bilingual teachers and bilingual students' lack of foreign language proficiency have been a development bottleneck of bilingual teaching. Researchers put forward some solutions from the point of view of university management. However, these solutions neglect the subjective initiative of bilingual teachers and students and therefore are lack of sustainability. In order to solve the problem fundamentally, bilingual teachers and students need to shift their way of thinking, set up a growth mindset, give full play to their own motivation, enhance their ability of teaching and learning and promote sustainable development of bilingual teaching.
\end{abstract}

\section{Introduction}

Teachers' lack of bilingual teaching ability and students' inadequate foreign language proficiency is regarded as a development bottleneck of bilingual teaching in China ${ }^{[1]}$. Aiming at inadequacies in quality and quantity of bilingual teachers, Researchers proposed to send out domestic teachers to study or study tour abroad to enhance their language proficiency and professional quality. Meanwhile Universities can attract Chinese students studying abroad back to China and engage in bilingual teaching ${ }^{[2]}{ }^{[3]}$ or provide training for relevant teachers. These measures can improve bilingual teachers' teaching ability to some extent. However, they ignore mobilization of bilingual teachers' subjective initiative and are hard to promote continuous development of bilingual teaching. In order to solve the problem of bilingual teacher deficiency fundamentally and remove the development bottleneck of university bilingual teaching, bilingual teachers need to shift their mindsets, look upon their abilities from a developmental perspective, and fulfill their potential. The key is to cultivate bilingual teachers' growth mindset and turn them from the attitude of a teacher to a learner, who expands his/her ability, meets challenges and cultivates themselves to be a bilingual teacher of international view and with sense of competition.

Smooth implementation and excellent effect of bilingual teaching relies not only on quality of bilingual teachers but also on the bilingual students' recognition and language acceptance capability. Some universities provide extra English courses to prepare students for bilingual teaching. However, whether students will achieve anticipated effect from the courses ties in bilingual students' mindset. A bilingual student with growth mindset tends to make greater effort when meeting challenges of bilingual teaching and promote his/her foreign language skills and professional knowledge acquisition.

Therefore, removal of development bottleneck of bilingual teaching, effective cooperation of bilingual teachers and students, achievement of bilingual objectives and continuous development of bilingual teaching depends on cultivation of growth mindset of bilingual teachers and students so that they will look upon their abilities from a developmental point of view and fully fulfill their potentials. 


\section{Bottleneck Confronted by Bilingual Teaching}

At present, the main problems bilingual teaching comes across are that bilingual teachers' capacities should be improved urgently, there is a serious shortage of qualified bilingual teachers and bilingual students have not developed sufficient foreign language skills required by bilingual teaching. Although researchers and universities proposed some improvement strategies, the fundamental solution of the problem has not been achieved.

\subsection{Current Situation in Shortage of Bilingual Teachers}

Bilingual teaching puts forward higher requirements of teachers. However, teachers available in the universities do not possess relevant capacity structure. Bilingual teachers are expected to master reasonable knowledge and ability structure and be proficient in foreign language and other subject knowledge. Some researchers proposed that the first requirement to bilingual teachers should be excellent language ability so that they can engage in teaching a subject in English ${ }^{[4]}$. High language level enables bilingual teachers to interact with students according to their actual language ability and increase students' understandable input. The researchers also hold that subject knowledge plays the key role. Essentially, bilingual teachers are teachers of specialized courses, proficient in professional knowledge and teaching method of relative subject. In addition, such teachers should pay attention to subject frontier and be equipped with high professional quality. Furthermore, bilingual teaching requires bilingual teachers to have international vision and intercultural communication competence. Economy globalization, education internationalization and cultural diversification raise new requirements for talent cultivation. Two languages and cultures are organically integrated in bilingual teaching, which not only promotes subject knowledge, comprehensive quality and skill acquisition but also undertakes the task of heritage, communication and creation of culture. However, teachers that meet the above requirements are very scarce.

Aiming at the problem of deficiency in quality and quantity of bilingual teachers, researchers suggest that universities should select and send excellent subject teachers abroad for language training or introduce foreign teachers or people having studied abroad for certain degree to work in the universities as bilingual teachers. Moreover, universities can provide training and guidance for teachers available ${ }^{[2]}$. These measures can enhance subject teachers' bilingual teaching abilities, increase qualified bilingual teachers in quantity and offer a platform for teachers to cultivate bilingual teaching skills. However, they can not thoroughly resolve the problem of deficiency in bilingual teachers. On the one hand, most general universities and colleges have difficulty in bearing expenses of sending teachers abroad or introducing foreign teachers. And the actual effect of short-time training cannot be maintained due to lack of foreign language environment. On the other hand, the effect of various training and guidance depends on the motives of bilingual teachers to improve their abilities. Bilingual teachers willing to develop themselves will make full use of all kinds of methods and approaches to promote their foreign language skills, professional knowledge and classroom teaching ability. On the contrary, bilingual teachers unwilling to learn may accept any training opportunities universities provide passively and are reluctant to turn their role of teachers into that of learners even though they confront knowledge deficiency in bilingual teaching.

\subsection{Hinderance in Students’ Acceptance of Bilingual Teaching}

Students' foreign language skills are not sufficient for bilingual teaching. Most students’ listening, speaking and reading is below the requested level for bilingual teaching. The insufficient listening skills result from characteristics of national foreign language teaching and the lack of environment to apply the foreign language. Low level of listening skills may hinder language input and acquisition of professional knowledge. As was discovered by researchers, at higher education stage, teacher talk takes up $2 / 3$ of the classroom talk ${ }^{[5]}$. Teacher talk includes explanation, questioning, feedback, correction of students' wrong answers and adjust their own language, so is bilingual teaching. Therefore, student's main approach to acquisition of language and professional knowledge 
is listening and listening plays a crucial part in absorbing knowledge in the classroom.

Furthermore, students' reading capacity is insufficient to read original English textbooks and literature and prevent the absorbance of knowledge from English teaching materials. Students of bilingual teaching are challenged by dual objectives of language learning and subject content. Learning subject content through a foreign language is much more difficult and challenging to them. Therefore, preview becomes particularly important. Preview can take on various ways, the most basic of which is for the students to read their textbooks and get a general idea of what will be learned in the next class. However, if the textbooks are original English versions, which is an unfamiliar carrier for students to learn unacquainted subject content, reading ability of bilingual students will be challenged, and this will affect their interest and enthusiasm to learn the subject content. If the textbook is bilingual, students with lower level of reading skills and are less motivated by learning may turn to contents of their mother tongue.

Another crucial factor to influence bilingual teaching effect is students' spoken English levels. The "dumb English" phenomenon is common among English learners despite of years reform in English teaching and learning in China. College students present lower level of oral English compared with listening and reading skills. Spoken English level of bilingual students determines the effect of classroom interaction and the extent to which students master the classroom teaching materials. Classroom interaction reflects teaching effect of bilingual class. However, the low ability of students' spoken English places them at an even more disadvantaged position in the classroom talk and makes them more passive in knowledge learning.

The dominant problem faced with bilingual teaching is unqualified and insufficient bilingual teachers and low levels of students' foreign language skills. To meet this challenge and promote substantial development of bilingual teaching, bilingual teachers and students need to shift their mindset, look upon themselves from a developmental perspective and mobilize their initiatives.

\section{Cultivate Growth Mindset to Give full Play to Bilingual Students and Teachers' Potential}

The fundamental way to solve bilingual teaching problem, achieve its dual objectives and sustainable development lies in shift bilingual teachers and students' mindset and firmly establishing their growth mindsets. A mindset can be seen as incident of a person's world view or philosophy of life. It may be so firmly established that it creates a powerful incentive within these people or groups to continue to adopt or accept prior behaviors, choices, or tools ${ }^{[6]}$. Professor Carol Dweck from Stanford University divided mindset into fixed mindset and growth mindset. In her study, the division of two mindsets mainly results from people's different perspectives towards ability, challenge, setbacks and success ${ }^{[7]}$. people with fixed mindset believe that their intelligence is unchangeable and therefore they are keen on proving their intelligence, focusing on results and neglecting the process of study. While people with growth mindset consider that their intelligence can be developed and cultivated and therefore they make great efforts to study and explore their potential. They are also apt to persist in the face of difficulties and eventually make greater achievements.

\subsection{The Necessity of Cultivation of Bilingual Teachers' Growth Mindset}

To efficiently solve bilingual teaching problem, university bilingual teachers need to develop their growth mindsets. As some researchers argued, promotion of bilingual teachers' ability is the key to enhance bilingual teaching quality. However, it is a long-term process because bilingual teachers need to be proficient in subject content of the course, pay attention to its latest development and academic frontier. Meanwhile, bilingual teaching also requires bilingual teachers to consistently improve their foreign language skills ${ }^{[1]}$. Therefore, a bilingual teacher with great potential must be a teacher willing to learn and grow and define himself/herself as a teacher as well as a learner. Qualified bilingual teachers must be those have studied abroad for a degree was held by some researchers ${ }^{[8]}$. However, the number of these people is limited which restricts the development of bilingual teaching, mainly because they did not look on existing domestic teachers from a developmental point of view and mobilize these teachers' initiatives in their own 
development. This is unfavorable to fulfillment of bilingual teaching objectives.

Bilingual teacher with growth mindset will take advantage of various learning resources, supplement their knowledge and promote capability. Nowadays technology develops rapidly and all kinds of learning resources surround us, such as online learning videos, E-books, and journals and magazines home and abroad, etc. People can learn at any time or any place to replenish their knowledge pertinently and efficiently. The development of IT and popularity of electrical communication equipment exert completely different effects on different bilingual teachers. To bilingual teachers with fixed mindset, the Internet, smart phones, various webpages, chat tools and games occupy more and more of their time and attention. However, teachers with growth mindset tend to take advantage of the resources actively and make tremendous efforts to cultivate their capabilities and comprehensive quality. They study more attentively, pertinently and efficiently, which forms an enormous inner drive to push them work hard to be qualified bilingual teachers. This effort will build not only qualified bilingual teachers but also talents with international horizon. Therefore, there is no fundamental difference between qualified bilingual teachers and unqualified bilingual teachers with growth mindset. We can get rid of the difficult situation of bilingual teaching by mobilize the initiative of existing bilingual teachers. For example, universities can select teachers with growth mindset or cultivate growth mindset of existing teachers, encourage and motivate them to continuously enhance their English applying capacities and bilingual teaching abilities and finally cultivate them into bilingual talents with international vision and competition awareness.

\subsection{Necessity of Cultivation of Bilingual Students' Growth Mindset}

Bilingual teaching is more challenging to students compared with teaching in their mother tongue. The main objective of learning is still professional knowledge, however, through a foreign language. Actually, it is a dual objective which poses difficulty for students' learning and mastering of professional knowledge. Bilingual students with fixed mindset tend to turn to their mother tongue when they confront difficulties in learning or even give up learning this subject, which hinders improvement of English language skills and subject content.

On the contrary, bilingual students with growth mindset choose to study harder when they meet challenges and difficulties in bilingual studying, improve their language skills, overcome language barriers and make good preparation for bilingual classes. For example, when bilingual students with insufficient reading abilities have difficulties in reading original foreign language version of textbooks, they tend to increase their subject vocabularies and promote reading ability in various ways. Student with classroom listening difficulties will choose to work hard on their listening skills and increase understandable input by preview. For effective interaction with teachers in the classrooms, students with low levels of oral English will challenge themselves continuously to improve their spoken English. They will try to express themselves and subject content in foreign language and build positive interactive relationship with teachers in class. Finally, promotion of language skills will enhance studying and understanding of subject content and improvement in reading and listening skills will greatly increase understandable input of professional knowledge. Meanwhile classroom interaction promotes output of knowledge and skills and fulfill dual objectives of language acquisition and professional knowledge learning.

\section{Conclusion}

Aiming at the development bottleneck of bilingual teaching, researchers proposed some measures to solve the problem. However, their viewpoints neglect bilingual teachers and students' initiatives. The fundamental approach to solution of the problem lies in shift of mindsets, cultivate growth mindset of existing teachers and students and look on them from a developmental point of view. Then they will stretch themselves, grow and become qualified in bilingual teaching and learning, which will bring sustainable development of bilingual teaching. 


\section{Acknowledgement}

This paper is supported by scientific research fund of International Business School, Shandong Jiaotong University in 2016, "Study on Bilingual Teaching of Tourism Management from the perspective of requirement analysis” (R201606).

\section{References}

[1] Zhi Zou, Study on the Bottleneck and Solution of University Bilingual Teaching [J]. Education Exploration, 2009 (10): 68-69.

[2] Toujiao Fan, et,al. Difficulties and Countermeasures in Implementation of University Bilingual Teaching [J]. Journal of Educational Science of Hunan Normal University, 2009, 8 (3): 123-125.

[3] Jinbo Zhang, Danlu Shao, Bilingual Teacher Predicament and Breakthrough in Higher Vocational College of Sino-foreign Cooperative Education-Based on Intercultural Education [J]. Vacational \& Technical Education Forum, 2017 (11): 11-15.

[4] Yunfeng Lv, Xucai Liu, Study on Construction of Bilingual Teacher Professional Standard and Choice of Their Professional Development [J]. Education and Career, 2015 (9): 57-59.

[5] Kuran Puasa, Audi Asrifan, et.al,Classroom Talk in Bilingual Class Interaction [J]. Research in Pedagogy, 2017, 1 (7): 106-121.

[6] [DB/OL]. https://en.wikipedia.org/wiki/Mindset, 2018-05-04.

[7] Carol S. Dweck, Mindset-The New Psychology of Success [M]. New York: Random House, 2006: 15

[8] Lijing Wu, Research on Innovation of Bilingual Teaching Mode for Postgraduates in Local Colleges [C]. Advances in Economics, Business and Management Research, 2016 (20): 483-486. 